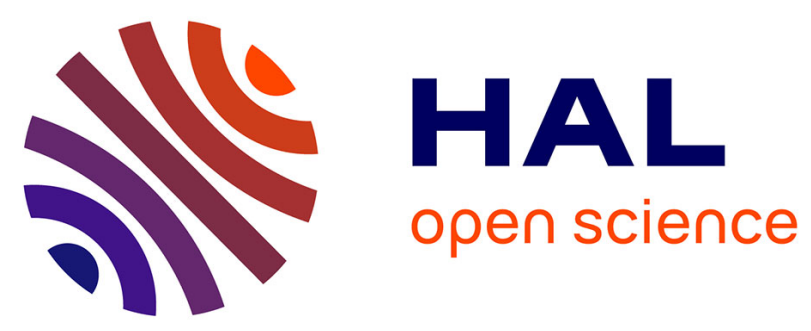

\title{
Increased selenium intake in elderly high fish consumers may account for health benefits previously ascribed to omega-3 Fatty acids.
}

\author{
Claudine Berr, Tasnime N. Akbaraly, Josiane Arnaud, Isabelle Hininger,
} Anne-Marie Roussel, Pascale Barberger-Gateau

\section{To cite this version:}

Claudine Berr, Tasnime N. Akbaraly, Josiane Arnaud, Isabelle Hininger, Anne-Marie Roussel, et al.. Increased selenium intake in elderly high fish consumers may account for health benefits previously ascribed to omega-3 Fatty acids.. Journal of Nutrition, Health \& Aging, 2009, 13 (1), pp.14-8. inserm00257791

\section{HAL Id: inserm-00257791 https://www.hal.inserm.fr/inserm-00257791}

Submitted on 4 Jun 2014

HAL is a multi-disciplinary open access archive for the deposit and dissemination of scientific research documents, whether they are published or not. The documents may come from teaching and research institutions in France or abroad, or from public or private research centers.
L'archive ouverte pluridisciplinaire HAL, est destinée au dépôt et à la diffusion de documents scientifiques de niveau recherche, publiés ou non, émanant des établissements d'enseignement et de recherche français ou étrangers, des laboratoires publics ou privés. 
Increased selenium intake in elderly high fish consumers may account for health benefits previously ascribed to omega-3 fatty acids

Berr Claudine ${ }^{1}$, Akbaraly Tasnime ${ }^{1}$, Arnaud Josiane ${ }^{2}$, Hininger Isabelle ${ }^{3,4}$, Roussel Anne-Marie ${ }^{3,4}$,Barberger Gateau Pascale ${ }^{5}$.

${ }^{1}$ INSERM U888 Pathologies du système nerveux: recherche épidémiologique et clinique; Université Montpellier I. Hôpital La Colombière, 39 avenue Charles Flahault,

BP 34493, F-34093 Montpellier, Cedex 5, France

${ }^{2}$ Département de biologie intégrée. Pôle de Biologie. CHU de Grenoble,, F-38043

Grenoble, Cedex 9, France

${ }^{3}$ INSERM, U884, Grenoble, F-38000, France

${ }^{4}$ LBFA, Université Joseph Fourier, Grenoble 1, F-38041, France

${ }^{5}$ INSERM U593 ; Université Bordeaux II, Bordeaux F-33000, France

Corresponding author: Claudine Berr, MD, PhD

INSERM U888, Hôpital La Colombière, 39 Avenue Charles Flahault, BP 34493, 34093 Montpellier, Cedex 5, France

Tel: 33 (0)4 99614 566, Fax : 33 (0)4 99614579

Mail: berr@montp.inserm.fr

Key words: Fish, fatty acids, selenium 


\begin{abstract}
Objective: to examine relationships between fish consumption and plasma selenium (Se) and red blood-cell fatty acid (RBC FA) profile in aged subjects. We hypothesised that the importance of Se has been underestimated when interpreting the beneficial effect of fish consumption on health.
\end{abstract}

Design: cross-sectional analysis of data from a prospective cohort study

Setting: the EVA study in Nantes, France (1991-2002)

Subjects: 200 subjects aged $\geq 69$ y with information on RBC FAs, plasma Se and completed food frequency questionnaires.

Methods: we examined correlations between the most abundant FAs, Se and number of fish meals per week. Linear regression models were used.

Results: Plasma Se was negatively correlated with RBC $\omega 6$ poly-unsaturated FA (PUFAs) and positively with $\omega 3$ PUFAs. Plasma Se, RBC $\omega 3$ PUFAs, docosahexaenoic acid (DHA) and eicosapentaenoic acid (EPA) increased with fish consumption. Conversely, levels of $\omega 6$ PUFAs were lower in the highest fish consumption group. All associations between plasma Se and fish consumption remained significant when adjusting for $\omega 6$ PUFAs alone or additionally for age, sex, education, diabetes, hypertension, dyslipidemia, cardiovascular diseases, and broad food categories (meat, eggs, dairy products, cereals, fruit and vegetable). Associations between $\omega 3$ PUFAs and fish also remained significant in the same model independently of Se. In linear regression models adjusted for demographic indicators, fish consumption explained only $2.6 \%$ of the variance in RBC $\omega 3$ FAs $(6.2 \%$ for $\omega 6)$ but as much as $15 \%$ of the variance in plasma selenium.

Conclusions: The observed health benefits of fish consumption in the elderly could be related not only to the increase in $\omega 3$ FA intake but also to other nutrients such as selenium. It is important to consider this observation when interpreting associations between fish consumption and health status in the elderly, particularly with regard to brain function. 


\section{Introduction}

The beneficial effect of fish consumption on elderly health and particularly on brain aging has been extensively studied (1). As fatty fish is the main dietary source of long-chain $\omega 3$ PUFA, this protective effect has been attributed to the long-chain $\omega 3$ PUFA content of fish $(2,3)$. In observational studies, high consumption of fish long-chain $\omega 3$ PUFA has been reported to reduce cognitive decline (4-6), risk of dementia (7-11), and to protect against stroke (12), cardiovascular diseases(13), metabolic syndrome $(14)$, diabetes $(15,16)$ and cancer(17). However, these effects on health are controversial (18) as fish contains other nutrients than $\omega 3$ PUFA (19) that could be involved in the health benefits related to its consumption.

In the EVA (Epidemiology of Vascular Aging) study, we previously reported that high levels of red blood cell (RBC) $\omega 6$ PUFA and low levels of RBC $\omega 3$ PUFA were associated with greater risk of cognitive decline (20). We also reported that lower plasma selenium (Se) concentrations, were associated with higher risk of cognitive decline $(21,22)$. Fish is an important contributor to both long-chain $\omega 3$ PUFA and Se intake in older persons (23) as a number of commonly consumed fish species contain high concentrations of Se.(24) Long-chain 03 PUFA (in particular eicosapentaenoic acid (EPA) and docosahexaenoic acid (DHA)) are synthesized from the essential FA alpha-linolenic acid, by elongating and desaturase enzymes. This enzymatic activity decreases with aging (25) and FA status is then, in ageing, more dependent on dietary supply of EPA and DHA.

We hypothesize that the role of Se has been underestimated when interpreting the beneficial effect of fish consumption on health. Thus, the present secondary analysis aimed to examine relationships between fish consumption, plasma Se concentration, and erythrocyte FA composition in older people. 


\section{Methods}

\section{Study population}

The aims, design and funding of the 9-year longitudinal EVA study have been previously described $(22,26)$. The study protocol was approved by the ethics committee of Hospital of Kremlin-Bicêtre, (Paris). Signed informed consent was obtained from all participants at enrolment in 1991-1993. Follow-up examinations were conducted every 18 months to 2 years until 2001-2002. In 1995-1997 (wave 3 ), due to financial limitations, only 342 blood samples, selected in chronological order, were analyzed for determination of erythrocyte FAs (20) (see figure 1). During the last follow-up of the EVA study in 2001-2002 (wave 6), volunteers answered the self-administered food frequency questionnaire (FFQ) and had blood sampled for plasma selenium determination. Out of the 342 selected subjects in 1995-1997, 200 had completed FFQs and blood sampling. These subjects did not differ from the initial subgroup for any of their demographic or health characteristics (data not shown).

As shown in figure 1, determinations of RBC-membrane FAs were performed more than 4 years before FFQ and plasma Se determination. We hypothesized that nutritional habits remained stable and we partially tested this hypothesis by examining the associations between baseline plasma Se determinations(19911993) and wave 6 Se determinations (2000-2001). The two determinations are highly correlated $(r=0.43, p<0.001)$. Furthermore even 9 years before the FFQ administration, the association between plasma Se concentration and fish consumption (in quartiles) was clear. Mean baseline selenium value (sd) was $1.00 \mu \mathrm{mol} / \mathrm{l}$ ( 0.19) in quartile,1.07 (0.17) in quartile 2, $1.11(0.17)$ in quartile 3 and $1.14(0.17)$ in quartile $4(p=0.0007)$.

\section{Data collection}

Self-administered food frequency questionnaire

A self-administered food frequency questionnaire assessed dietary habits, based on each meal (breakfast, lunch and dinner) and on consumption of each of the following foods: fish, eggs, milk and dairy products, cereals and starchy foods, fruit and vegetable, sugar and chocolate products. 
Plasma Se $(\mu \mathrm{mol} / \mathrm{l})$ was determined as previously reported(27). FA composition of red blood cells (RBC) was determined as described previously (20).

\section{General information}

During face-to-face interviews conducted by trained psychologists, we gathered information on standard demographic variables and health status. Educational achievement was divided into two levels: no school or primary school (primary school) versus high school or university (high school or above). BMI was calculated. Subjects who reported a medical history of diabetes or who used antidiabetic drugs or those who had a plasma glucose level $\geq 7.80 \mathrm{mmol} / \mathrm{l}(1.40 \mathrm{~g} / \mathrm{l})$ were considered to be diabetic. Hyperlipidemia was defined as having LDL cholesterol $\geq 4.1 \mathrm{mmol} / \mathrm{l}(2.80 \mathrm{~g} / \mathrm{l})$ or using lipid-lowering drugs or reporting a hyperlipidemia medical history. Subjects with systolic blood pressure $\geq 140 \mathrm{~mm}$ $\mathrm{Hg}$ or diastolic blood pressure $\geq 90 \mathrm{~mm} \mathrm{Hg}$, or using hypertensive drugs or those reporting a medical history of hypertension were considered to be hypertensive. History of vascular diseases was defined as self-reported history of myocardial infarction, angina pectoris and stroke or use of vascular drugs.

A global cognitive test, the Mini Mental Status Examination (MMSE) (28) and the Digit Symbol Substitution (DSS) from the Wechsler Adult Intelligence ScaleRevised (WAIS-R) that measures sustained attention and logical reasoning (29) were analysed in the current study. Cognitive assessment at wave 6 is available only on a sample of 143 subjects due mostly to refusal of cognitive evaluation.

\section{Statistical analysis}

From the food frequency questionnaire, we first examined the numbers of meals with fish consumption per week. In this population living on the Atlantic coast of France, the range was large [0-12] and we constructed dummy variables in 4 classes according to the quartile distribution: one meal with fish consumption or fewer per week $(n=45), 2$ meals per week $(n=51), 3$ meals per week $(n=34)$ and 4 or more meals per week $(n=70)$. Few subjects had a low consumption, only 3 never ate fish and only ten less than once a week.

The number of FA species identified was large. We restricted analyses to a limited number of chemical families and the most abundant FAs: saturated fatty 
acids (SFAs), mono-unsaturated fatty acids (MUFAs) and PUFAs ( $\omega 3$ and $\omega 6$ ), DHA (22:6 $\omega 3)$, EPA (20:5 $\omega 3)$, arachidonic acid (AA) $(20: 4 \omega 6)$ and linoleic acid $(18: 2 \omega 6)$.

Qualitative and quantitative characteristics were compared between the four classes of fish consumers respectively by analysis of variance and chi-square test. We examined correlation between the selenium determinations and fatty acid membrane composition using Pearson's correlation coefficient.

In order to examine the respective link between fish consumption (dependant variable in 4 classes) and biological measurements (Se and FA), linear regression models were used ( Proc REG from SAS software). The lowest intake level of fish (one or fewer fish meals per week) was the referent category. Covariates systematically included in the models were age, sex and education.

Moreover, we included as potential confounding variables factors that had previously been associated with fish consumption in a previous study (30), even though some were not statistically significantly associated with it in this sample: diabetes, hypertension, dyslipidemia and a history of cardiovascular disease. We further added the consumption of other broad food categories, each considered in two classes, with respect to median values in the population.

Statistical significance was defined by a $p$ value $<0.05$. Statistical analyses were performed using SAS software version 9.1 (SAS Institute, Inc. Cary, North Carolina). 


\section{Results}

As indicated in table 1, 35\% of subjects were heavy fish consumers whereas $22.5 \%$ ate fish less than once a week. Compared to moderate fish consumption ( 2 or 3 fish meals a week), low and high fish consumption is more frequently associated with hypertension. MMSE score did not differ between the 4 groups but there was an association between DSS performance and fish consumption, lower fish consumers having the poorest DSS performances. This association, described on a small sub-sample $(n=143)$, did not remain significant when adjusting for age, sex and education.

Se concentration increased linearly with fish consumption from $0.92 \mu \mathrm{mol} / / \mathrm{l}$ in the lowest consumption group to $1.10 \mu \mathrm{mol} / \mathrm{l}$ in the highest group. Similarly, increases were observed for total $\omega 3$ PUFAs (from $9.2 \%$ to $10.3 \%$ ), both for DHA and EPA. Conversely, levels of total $\omega 6$ PUFAs were lower in the highest fish consumption group $(27.3 \%)$ compared to subjects with the lowest consumption per week (28.6\%).

Se was negatively correlated with total $\omega 6$ PUFA $(r=-0.21, p \leq 0.01)$ and its major component $A A(r=0.15, p \leq 0.05)$. Conversely, correlation between plasma Se and total $\omega 3$ PUFA was positive $(r=0.22, p \leq 0.01)$. This positive association was found both for DHA $(r=0.22, p \leq 0.01)$ and for EPA $(r=0.21, p \leq 0.01)$. No correlation was observed between Se and SFAs $(r=0.05, P>0.05)$ or MUFAs $(r=0.025, P>0.05)$. Therefore, these two FAs groups were not considered in further analyses.

Fish consumption remained positively associated with plasma Se as well as with $\omega 3$ PUFAs and, negatively with $\omega 6$ PUFAs after adjusting for demographic indicators (table 2) The model explained $15 \%$ of the variance of selenium whereas the proportion of variance explained was much lower for PUFAs, $6.2 \%$ for $\omega 6,2.6 \%$ for $\omega 3$. These effects were mostly observed in the two highest classes of consumption. These associations were not modified when further adjusted for diabetes, hypertension, dyslipidemia, history of cardiovascular diseases and other food categories (data not shown). 


\section{Discussion}

In this secondary cross-sectional analysis of a sample of elderly subjects, fish consumption was independently positively associated with both plasma Se and RBC-membranes $\omega 3$ PUFAs. The significant linear increase of both plasma Se and RBC-membrane $\omega 3$ PUFA levels with increasing fish consumption suggests that the beneficial effect of fish consumption on health may not be exclusively attributed to long-chain $\omega 3$ PUFAs.

These independent associations remained significant even when controlling for a large number of demographic and health factors and broad food categories. These relationships are in agreement with previous reports (32-34). In a Chinese rural population, plasma Se and glutathione peroxidase activity were positively associated with RBC DHA. In that same population, $\omega 3$ PUFAs were negatively associated with coronary and hypertensive heart disease mortality whereas Se levels were negatively associated with chronic bronchitis, emphysema and respiratory heart diseases (32). In Greenland Inuits, Se intake has always been high and is closely linked to the consumption of traditional foods of marine origin. In addition, Se blood concentrations are highly correlated with long-chain marine FAs (34). In a Finnish population, the comparison of high fish consumers to low fish consumers (41 pairs, mean age 54.3 y) showed higher plasma $\omega 3$ PUFAs and lower $\omega 6$ in high fish consumers (33).

Long-chain n-3 PUFAs as found in some fish are susceptible to lipid peroxidation forming lipid hydroperoxides. Se, as the selenoenzymes GPx1 and GPx4, is required for the removal of these lipid hydroperoxides before they can be broken down to undesirable products (35). Thus a high oily fish intake probably requires a high Se intake to avoid deleterious health effects. Luckily, fish have a good Se content. The other role of Se in relation to fatty acid metabolism relates to peroxide tone which is lowered by the GPxs thereby down-regulating eicosanoid metabolism and associated physiological events(35).

Our results show that the highest fish consumers who also had the highest plasma selenium and RBC-membrane $\omega 3$ PUFA concentrations had the best cognitive performances in crude analyses. Therefore apparent protection against dementia in fish consumers, documented by previous epidemiological studies in 
large cohorts $(19,31,32)$ should not be exclusively attributed to long-chain $\omega-3$ PUFAs but might involve a possible synergistic effect between selenium and long chain $\omega 3$ FA intakes.

The present study has however a number of limitations. First, The FFQ was completed retrospectively by the participants and we used a global indicator of fish consumption in this population of elderly subjects. We estimated the frequency of fish consumption but not the quantities, nor the type of fish consumed. The amount of PUFAs and Se vary largely according to fish species(24). PUFA content of fish is highly dependent on its fat content (fatty fish such as salmon, mackrel, herring, trout, tuna having a higher content than lean fish such as plaice or cod) and on whether it is farmed or wild. In addition, the cooking process (steamed, baked, or fried) may also considerably influence the final FA content of the dish. As regards Se, fish processing (cooking or enzyme and salt treatment) has not been reported to affect Se bioavailability (36).

Second, our sample size was limited by attrition during follow-up which limits the study power for comparing characteristics and health status of fish consumers. Multivariate results for cognition are not presented due to limited sample size and poor statistical power. Third, evaluation of the reported parameters was not performed simultaneously. Nevertheless, despite these limitations, the statistical link between fish consumption and biological indicators is powerful enough to allow us to hypothesize that the beneficial effect of fish consumption may not be limited to $\omega 3$ PUFAs alone but can also be attributed to Se. Besides Se, other micronutrients (for example iodine) may also be involved as already suggested $(19,31,32)$. It is important to take our findings into account when discussing and interpreting associations between fish consumption and health status, particularly brain function, in the elderly.

\section{Acknowledgments :}

N. T Akbaraly was supported by a grant from the French Alzheimer's disease Association. The EVA study was carried out under an agreement between INSERM and the Merck, Sharp and Dohme-Chibret Laboratories (WestPoint, PA) and was supported by EISAI laboratory (France) 


\section{References}

1. Mozaffarian D, Rimm EB. Fish intake, contaminants, and human health: evaluating the risks and the benefits. Jama. 2006 Oct 18;296(15):1885-99.

2. Rodriguez-Cruz M, Tovar AR, del Prado M, Torres N. [Molecular mechanisms of action and health benefits of polyunsaturated fatty acids]. Rev Invest Clin. 2005 MayJun;57(3):457-72.

3. Bourre JM. Dietary omega-3 Fatty acids and psychiatry: mood, behaviour, stress, depression, dementia and aging. J Nutr Health Aging. 2005;9(1):31-8.

4. Kalmijn S, van Boxtel MP, Ocke M, Verschuren WM, Kromhout D, Launer LJ. Dietary intake of fatty acids and fish in relation to cognitive performance at middle age. Neurology. 2004 Jan 27;62(2):275-80.

5. Solfrizzi V, Colacicco AM, D'Introno A, Capurso C, Torres F, Rizzo C, et al. Dietary intake of unsaturated fatty acids and age-related cognitive decline: A 8.5-year follow-up of the Italian Longitudinal Study on Aging. Neurobiol Aging. 2005 Oct 24.

6. Morris MC, Evans DA, Tangney CC, Bienias JL, Wilson RS. Fish consumption and cognitive decline with age in a large community study. Arch Neurol. 2005 Dec;62(12):184953.

7. Kalmijn S, Launer LJ, Ott A, Witteman JCM, Hofman A, Breteler MMB. Dietary fat intake and the risk of incident dementia in the Rotterdam Study. AnnNeurol. 1997 1997;42(5):776-82.

8. Barberger-Gateau P, Letenneur L, Deschamps V, Peres K, Dartigues JF, Renaud S. Fish, meat, and risk of dementia: cohort study. Bmj. 2002 Oct 26;325(7370):932-3.

9. Morris MC, Evans DA, Bienias JL, Tangney CC, Bennett DA, Wilson RS, et al. Consumption of fish and n-3 fatty acids and risk of incident Alzheimer disease. Arch Neurol. 2003 Jul;60(7):940-6.

10. Huang TL, Zandi PP, Tucker KL, Fitzpatrick AL, Kuller LH, Fried LP, et al. Benefits of fatty fish on dementia risk are stronger for those without APOE epsilon4. Neurology. 2005 Nov 8;65(9):1409-14.

11. Barberger-Gateau P, Raffaitin C, Letenneur L, Berr C, Tzourio C, Dartigues JF, et al. Dietary patterns and risk of dementia: The Three-City cohort study. Neurology. 2007 Nov 13;69(20):1921-30.

12. Bouzan C, Cohen JT, Connor WE, Kris-Etherton PM, Gray GM, Konig A, et al. A quantitative analysis of fish consumption and stroke risk. Am J Prev Med. 2005 Nov;29(4):347-52.

13. Konig A, Bouzan C, Cohen JT, Connor WE, Kris-Etherton PM, Gray GM, et al. A quantitative analysis of fish consumption and coronary heart disease mortality. Am J Prev Med. 2005 Nov;29(4):335-46.

14. Carpentier YA, Portois L, Malaisse WJ. n-3 fatty acids and the metabolic syndrome. Am J Clin Nutr. 2006 Jun;83(6 Suppl):1499S-504S.

15. Delarue J, LeFoll C, Corporeau C, Lucas D. N-3 long chain polyunsaturated fatty acids: a nutritional tool to prevent insulin resistance associated to type 2 diabetes and obesity? Reprod Nutr Dev. 2004 May-Jun;44(3):289-99.

16. Nettleton JA, Katz R. n-3 long-chain polyunsaturated fatty acids in type 2 diabetes: a review. J Am Diet Assoc. 2005 Mar;105(3):428-40.

17. Granados S, Quiles JL, Gil A, Ramirez-Tortosa MC. Dietary lipids and cancer. Nutr Hosp. 2006 May;21 Suppl 2:42-52, 44-54.

18. Hooper L, Thompson RL, Harrison RA, Summerbell CD, Ness AR, Moore HJ, et al. Risks and benefits of omega 3 fats for mortality, cardiovascular disease, and cancer: systematic review. Bmj. 2006 Apr 1;332(7544):752-60. 
19. Savige GS. Candidate foods in the Asia-Pacific region for cardiovascular protection: fish, fruit and vegetables. Asia Pac J Clin Nutr. 2001;10(2):134-7.

20. Heude B, Ducimetiere P, Berr C. Cognitive decline and fatty acid composition of erythrocyte membranes--The EVA Study. Am J Clin Nutr. 2003 Apr;77(4):803-8.

21. Berr C, Balansard B, Arnaud J, Roussel AM, Alperovitch A. Cognitive decline is associated with systemic oxidative stress: the EVA study. Etude du Vieillissement Arteriel. J Am Geriatr Soc. 2000 Oct;48(10):1285-91.

22. Akbaraly NT, Hininger-Favier I, Carrière I, Arnaud J, Gourlet V, Roussel AM, et al. Plasma Selenium over time and cognitive decline in the elderly: results from the EVA study Epidemiology 2007;18(1):52-8.

23. Gonzalez S, Huerta JM, Fernandez S, Patterson EM, Lasheras C. Food Intake and Serum Selenium Concentration in Elderly People. Ann Nutr Metab. 2006 Jan 3;50(2):126-31. 24. Souci S, Fachman W, Kraut H, editors. Food composition and nutrition tables. Stutgart: Medpharm Scientific publishers; 2000.

25. Yehuda S, Rabinovitz S, Carasso RL, Mostofsky DI. The role of polyunsaturated fatty acids in restoring the aging neuronal membrane. Neurobiol Aging. 2002 Sep-Oct;23(5):84353.

26. Berr C, Richard MJ, Roussel AM, Bonithon-Kopp C. Systemic oxidative stress and cognitive performance in the population-based EVA study. Etude du Vieillissement Arteriel. Free Radic Biol Med. 1998 May;24(7-8):1202-8.

27. Arnaud J, Prual A, Preziosi P, Favier A, Hercberg S. Selenium determination in human milk in Niger: influence of maternal status. J Trace Elem Electrolytes Health Dis. 1993 Dec;7(4):199-204.

28. Folstein M, Anthony JC, Parhad I, Duffy B, Gruenberg EM. The meaning of cognitive impairment in the elderly. JAmGeriatrSoc. 1985 1985;33:228-235:228-35.

29. Wechsler D. The Wechsler Adult Intelligence Scale-Revised. New-York; 1981.

30. Barberger-Gateau P, Jutand MA, Letenneur L, Larrieu S, Tavernier B, Berr C. Correlates of regular fish consumption in French elderly community dwellers: data from the Three-City study. Eur J Clin Nutr. 2005 May 18;59:817-25.

31. Dahl L, Bjorkkjaer T, Graff IE, Malde MK, Klementsen B. [Fish--more than just omega 3]. Tidsskr Nor Laegeforen. 2006 Jan 26;126(3):309-11.

32. Wang Y, Crawford MA, Chen J, Li J, Ghebremeskel K, Campbell TC, et al. Fish consumption, blood docosahexaenoic acid and chronic diseases in Chinese rural populations. Comp Biochem Physiol A Mol Integr Physiol. 2003 Sep;136(1):127-40.

33. Anttolainen M, Valsta LM, Alfthan G, Kleemola P, Salminen I, Tamminen M. Effect of extreme fish consumption on dietary and plasma antioxidant levels and fatty acid composition. Eur J Clin Nutr. 1996 Nov;50(11):741-6.

34. Hansen JC, Deutch B, Pedersen HS. Selenium status in Greenland Inuit. Sci Total Environ. 2004 Sep 20;331(1-3):207-14.

35. Girotti AW. Lipid hydroperoxide generation, turnover, and effector action in biological systems. J Lipid Res. 1998 August 1, 1998;39(8):1529-42.

36. Fox TE, Van den Heuvel EG, Atherton CA, Dainty JR, Lewis DJ, Langford NJ, et al. Bioavailability of selenium from fish, yeast and selenate: a comparative study in humans using stable isotopes. Eur J Clin Nutr. 2004 Feb;58(2):343-9. 
Table 1a: Demographic characteristics, health indicators and biological measurements according to fish consumption frequency (meals/ week)

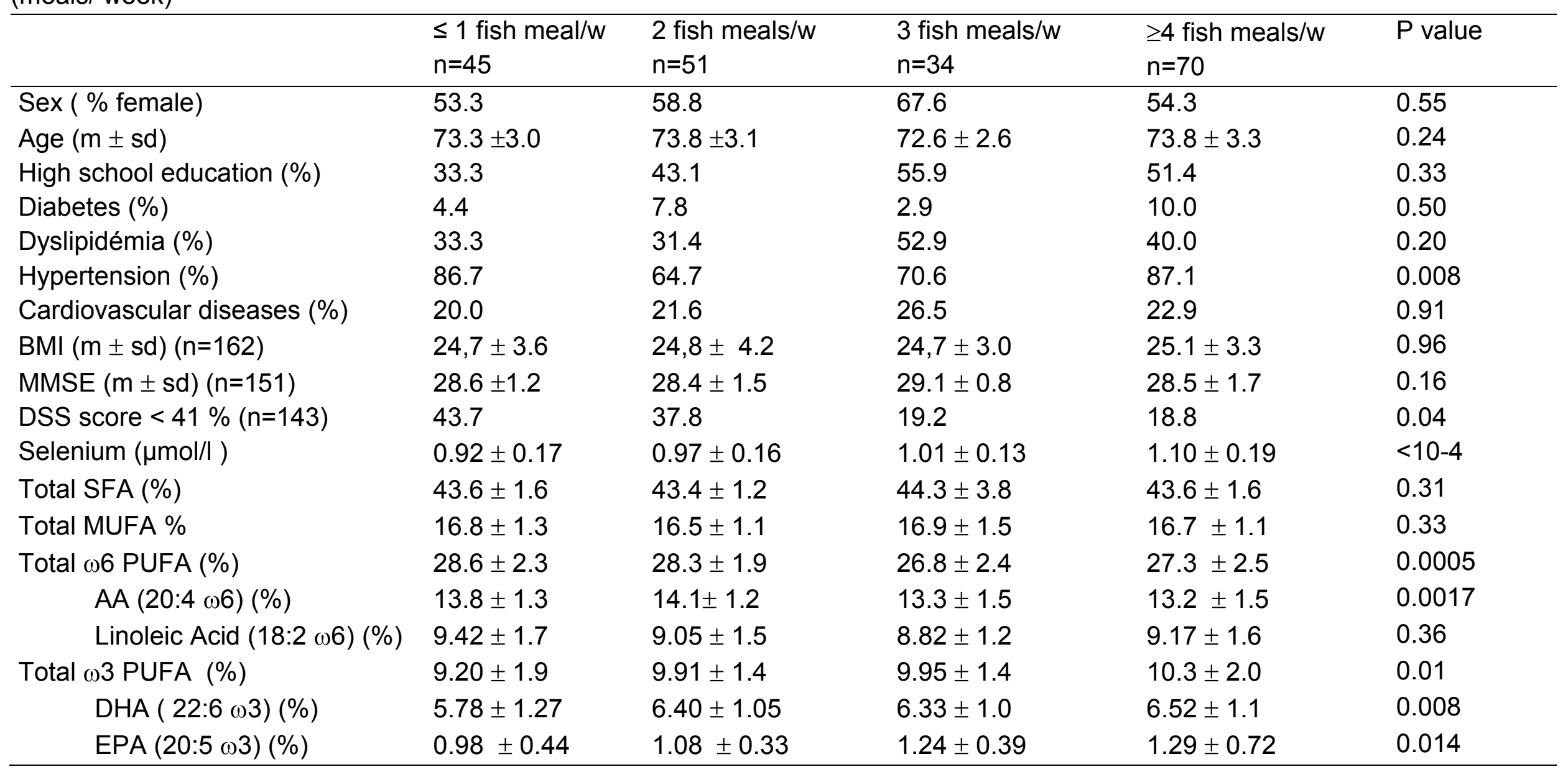

$\mathrm{BMI}=$ Body Mass Index $=$ weight $/$ heigh ${ }^{2} ;$ MMSE = Mini Mental Status Examination; DSS = Digit Symbol Substitution FA expressed as percent of total fatty acids; SFA= Saturated Fatty Acids; MUFA= Monounsaturated Fatty Acids; PUFA= Polyunsaturated Fatty Acids; AA= Arachidonic Acid; DHA= Docosa Hexaenoic Acid; EPA= Eicosa Pentaenoic Acid 
Table 1b: Dietary habits associated to fish consumption frequency ( $\%$ above the median of the sample)

\begin{tabular}{|c|c|c|c|c|c|}
\hline & $\begin{array}{l}\leq 1 \text { fish } \text { meal/w } \\
n=45\end{array}$ & $\begin{array}{l}2 \text { fish meals/w } \\
n=51\end{array}$ & $\begin{array}{l}3 \text { fish meals } / w \\
n=34\end{array}$ & $\begin{array}{l}\geq 4 \text { fish meals } / w \\
n=70\end{array}$ & $P$ value \\
\hline Meat & 44.4 & 52.9 & 50.0 & 57.1 & 0.61 \\
\hline Dairy products & 46.7 & 54.9 & 50.0 & 50.0 & 0.88 \\
\hline Eggs & 42.2 & 39.2 & 41.2 & 60.0 & 0.07 \\
\hline Cereals and starchy foods & 33.0 & 33.0 & 50. & 33.0 & 0.32 \\
\hline Fruits \&Vegetables & 51.1 & 51.0 & 38.2 & 55.7 & 0.42 \\
\hline
\end{tabular}


Table 2: Fish consumption ( $\leq 1,2,3, \geq 4$ meals per week ): association with selenium and PUFA levels in an elderly population ( $n=200$ ): results of linear regression models including systematically age, sex and education (Reference $\leq 1 \mathrm{meal} /$ week, $\mathrm{n}=45$ )

\begin{tabular}{|c|c|c|c|c|c|c|c|}
\hline & \multirow{2}{*}{\multicolumn{2}{|c|}{$\begin{array}{l}2 \text { meals/week } \\
n=51\end{array}$}} & \multirow{2}{*}{\multicolumn{2}{|c|}{$\begin{array}{l}3 \text { meals/week } \\
n=34\end{array}$}} & \multirow{2}{*}{\multicolumn{2}{|c|}{$\begin{array}{l}\geq 4 \text { meals/week } \\
n=70\end{array}$}} & \multirow{3}{*}{$\mathrm{R}^{2}$} \\
\hline & & & & & & & \\
\hline & $\beta^{*} \pm s d$ & $p$ & $\beta^{*} \pm s d$ & $p$ & $\beta^{*} \pm s d$ & $p$ & \\
\hline Selenium & $0.046 \pm 0.035$ & 0.19 & $0.076 \pm 0.040$ & 0.06 & $0.17 \pm 0.03$ & $<0.0001$ & 0.149 \\
\hline Total PUFA $\omega 6$ & $-0.30 \pm 0.47$ & 0.52 & $-1.88 \pm 0.53$ & 0.0005 & $-1.34 \pm 0.44$ & 0.003 & 0.062 \\
\hline Total PUFA $\omega 3$ & $0.74 \pm 0.37$ & 0.04 & $0.77 \pm 0.41$ & 0.06 & $1.14 \pm 0.34$ & 0.001 & 0.026 \\
\hline $\mathrm{DHA}(22: 6 \omega 3)$ & $0.60 \pm 0.23$ & 0.01 & $0.51 \pm 0.26$ & 0.06 & $0.73 \pm 0.21$ & 0.001 & 0.040 \\
\hline $\operatorname{EPA}(20: 5 \omega 3)$ & $0.10 \pm 0.11$ & 0.37 & $0.28 \pm 0.12$ & 0.03 & $0.31 \pm 0.10$ & 0.003 & 0.027 \\
\hline
\end{tabular}

${ }^{*} \beta$ regression coefficient is expressed for 1 unit 
Figure 1 : Selection of the studied population

Time

Number of

volunteers

Additional

Evaluation

volunteers
1991-1993

1389

2000-2001

1995-1997

1188

702

RBC fatty acids $(n=342)$

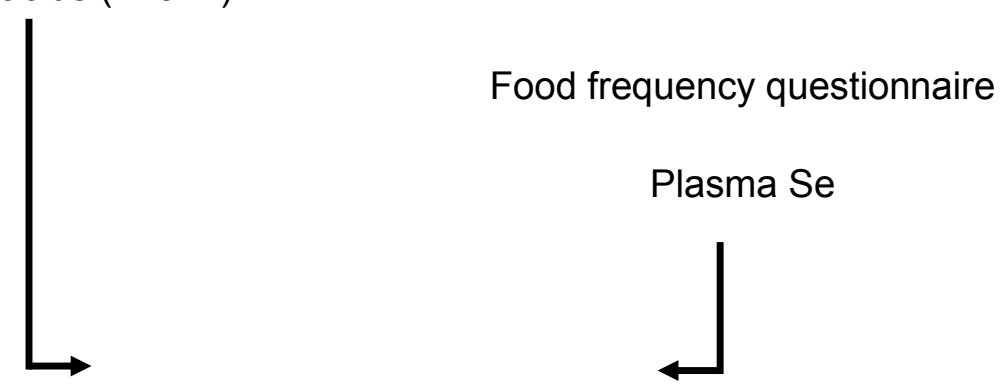

200 eligible volunteers

with RBC fatty acids, plasma Se and FFQ 